\title{
The Impact of Carbon Emission Trade on Power Generation
}

\author{
WANG Hai-chao ${ }^{1, a}$, LIU Dun-nan ${ }^{2, b}$, YANG Xiao-yue ${ }^{1, c}$, YING Yu-hang ${ }^{2, d}$ \\ ${ }^{1}$ Anhui grid power trade center, Anhui 230000, P.R. China \\ ${ }^{2}$ North China Electric Power University, Beijing 102206, P.R. China \\ aahdljh@163.com, liudunnan@163.com, ${ }^{\text {c4} 490935411 @ q q . c o m, ~}{ }^{\text {d }}$ liviayyh@126.com
}

Keywords: Carbon Emission Trade; Trade Mechanism; Electricity Generation Space; Electricity Generating Cost; Business Decision.

\begin{abstract}
World widely speaking, the power industry is an important area of carbon emission and carbon reduction. It is also one of the main carbon trading market. Carbon-constrained electricity market will profoundly alter the original model of electricity production and electricity trading. Consequently, the behaviors in all the main electricity market will have a qualitative change. This paper analyzes the trading rules of Shanghai carbon trading market, including the ways of carbon trade, quota allocation and power industries baseline. Furthermore, in-depth study of the impact of carbon constraints on electricity generation in Shanghai grid is carried out. Taking the Shanghai grid as an example, the study focus on the generation space, generation cost and business decisions for generation enterprises under the constraints of low carbon.
\end{abstract}

\section{Introduction}

With the establishment of China's carbon trade market, in order to achieve our nation' s carbon emission reduction targets, the power industry has become one of the most important market players. In China, there is a large amount of carbon emission in power industry. Carbon dioxide emission in power industry is nearly $50 \%$ of the total emissions in 2010, which is far more than developed countries. It shows the tremendous pressure on carbon emissions and great potential of China's power industry. In the situation of low carbon economy, the traditional power industry will face huge changes both in internal development and external environment.

For Shanghai power industries, the direct impact on carbon markets is the need to manage carbon emission, and it may increase production costs for the completion of carbon reduction. But for enterprises having advanced technology and high level of management, they just need to make good preparations, and it is entirely possible to benefit from participating in the carbon emissions trade market. The quota of power generation enterprises is mainly affected by industrial baseline and actual carbon intensity. If the actual carbon intensity of the enterprises is lower than the reference line in the industry, they can obtain the relative surplus quotas and benefit from carbon trading.

\section{Power space of power enterprise under low-carbon constraints}

$\mathrm{CO}_{2}$ emission reduction plan of our country is that $\mathrm{CO}_{2}$ emission of unit GDP (carbon intensity) in 2020 will reduce by $40 \%-50 \%$ comparing to that of 2005 . In order to achieve it, compulsory administrative means and distributing carbon emission methods based on target constrains method should be taken in the second period of distributing carbon emission right.

Under compulsory carbon emission constrains, the power space of power plant is influenced by initial coal quota and average emission factor of power plant. The amount of possible generation $Q_{i j}$ of power plant $\mathrm{j}$ in the $\mathrm{i}$ year is as follows:

$$
Q_{i j}=\frac{A_{i j}^{0}}{e_{i-1, j}}
$$


In which, $A_{i j}^{0}$ is the distributing initial carbon emission quota of the power plant in the i year. $e_{i-1, j}$ is average $\mathrm{CO} 2$ emission factor in last year.

Presuming that annual contract volume (scheduled energy) of the power plant is $Q_{i j}^{0}$, then there are three situations:

(1) The amount of possible generation is higher than contact volume

If $Q_{i j}>Q_{i j}^{0}$, which means the amount of possible generation is lower than contact volume. Suggesting that carbon emission level of the power plant is lower than average level. And spare carbon emission right can be traded or storage.

(2) The amount of possible generation is equal to contact volume

If $Q_{i j}=Q_{i j}^{0}$, which means the amount of possible generation is exactly equal to contact volume, Suggesting that carbon emission level of the power plant is correspond to average level. Generation target can be achieved under carbon emission limit in the i year.

(3) The amount of possible generation is lower than contact volume

If $Q_{i j}<Q_{i j}^{0}$, which means the amount of possible generation is higher than contact volume. Although some emission implements have be taken, generation demand still can not be met under existing carbon emission quota. Therefore future carbon emission right can be overdrawn and emission right can be bought in trade market.

\section{Generation cost of power enterprise under the constraints of low carbon}

The main purpose of carbon emission trade is to control development of industries which are high energy consumption and high pollution, so that the carbon emission target can be achieved. Carbon emission trade may impact on various power enterprises. For high energy consumption enterprise, more carbon emission right should be bought, therefore generating cost will be increased. On the other hand, low energy consumption enterprises have spare carbon quotas and can make a profit by selling spare carbon quotas.

Increased cost $C_{j}$ of high energy consumption enterprises is taken here:

$C_{j}=P_{c} \times\left(N_{j}-A_{j}\right)$

In which, $C_{j}$ is taken as increased cost of enterprise $\mathrm{j}, P_{c}$ is taken as trade price of carbon emission right. $A_{j}$ is taken as the initial quota of that enterprise. $N_{j}$ is taken as carbon emission under normal generating situation.

$N_{j}=Q_{c} \times e_{j}$

In which, $Q_{c}$ is taken as contrast capacity of power plants, $e_{j}$ is taken as carbon emission factor.

(2) Increased profit of low energy consumption units

The profit of low energy consumption units in carbon emission trade is taken here:

$R_{j}=P_{c} \times\left(A_{j}-N_{j}\right)$

In which, $R_{j}$ is taken as extra profit of enterprise $\mathrm{j}$.

\section{Business decision of power enterprises under the constraints of low carbon}

At present, In order to conform generating hours of each power plant, grid companies are based on generating hours and principle of impartiality and openness when distribute power plans. Power plants confirm generation schedules of this year by synthetically considering pre-setting generating hours and unit installed capacity of this year. However, units of high energy consumption with limit of carbon quota is likely to can not accomplish the power plan under carbon emission trade. But units of 
low energy consumption still have spare carbon on the premise of accomplishing power plan. Therefore, different power enterprises is faced with different business decisions under the impact of carbon emission trade. Under the constraints of carbon emission, there are three categories of relationships between amount of possible power capacity $Q_{i j}$ of power plant $\mathrm{j}$ and contract volume ( schedule energy):

(1) Amount of possible power capacity is higher than schedule energy

If $Q_{i j}>Q_{i j}^{0}$, amount of possible power capacity is higher than schedule energy, which means this power plant has spare carbon emission right. Therefore, purchasing generation rights or selling carbon emission indicators are the main possible generating decisions. From economic perspective considering, generating decision will be carried out based on marginal revenue of the two methods.

1) Purchasing generation rights

Under the principle of impartiality and openness, annual generating indicators of each power plants were confirmed. Extra generating rights should be purchased in trade market of generating rights if the power plant wants to generate more electricity.

Marginal revenue of purchasing generation rights=generation price-generation cost-price of generating transferring right

Amount of purchasing generation rights=amount of possible generating power- contract volume

2) Selling carbon emission indicators

In trade market of carbon emission rights, power generation subjects can sell spare carbon emission quotas to power plants which have insufficient carbon distribution.

Marginal revenue of selling carbon emission indicators=trade price of carbon emission rights/carbon emission factors

Amounts of selling carbon emission indicators=initial carbon quotas-amount of normal demanding carbon emission

(2) Amount of possible power capacity is lower than schedule energy

If $Q_{i j}<Q_{i j}^{0}$, amount of possible power capacity is lower than schedule energy, which means this power plant can not accomplish generation assignment under existing carbon emission quotas. Therefore, transferring generation rights or purchasing carbon emission rights are also possible generating decisions.

1) Transferring generation rights

Under the constraints of carbon emission, unit of high energy consumption can transfer extra generation rights to power plants which have insufficient generation rights through trade market of generation rights.

Marginal revenue of transferring generation rights=transferring price of generation rights

The amounts of transferring generation rights= contract volume-possible power capacity

2) Purchasing carbon emission rights

Units of high energy consumption can accomplish power capacity of annual generation rights by purchasing carbon emission rights in carbon trade market.

Marginal revenue of purchasing carbon emission rights= generation price-generation cost/trade price of carbon emission rights/carbon emission factors

The amount of purchasing carbon emission indicators=the amount of normal demanding carbon emission- initial carbon quotas

If marginal revenue of transferring generation rights is higher than marginal revenue of purchasing carbon emission rights, power plants should sell extra generation rights. On the other hand, if marginal revenue of transferring generation rights is lower than marginal revenue of purchasing carbon emission rights, power plants should purchasing carbon emission rights in carbon trade market. 


\section{Analysis on example}

Taking Shanghai grid as an example, generation space and the cost of generation units under the constraints of low carbon have been analyzed. The generation situation of generation enterprises is shown in Tab.1.

Tab.1 Generation space of units under carbon emission trade for Shanghai grid

\begin{tabular}{|c|c|c|c|c|c|c|}
\hline \multirow[t]{2}{*}{ Power plant } & \multirow[t]{2}{*}{ Unit } & $\begin{array}{l}\text { Installed } \\
\text { capacity }\end{array}$ & Contract volume & $\begin{array}{l}\text { Electricity under } \\
\text { carbon constraint }\end{array}$ & Volume difference & $\begin{array}{l}\text { Percentage of the } \\
\text { diffference }\end{array}$ \\
\hline & & $M W$ & $\begin{array}{c}\text { A hundred million } \\
k W \cdot h\end{array}$ & $\begin{array}{c}\text { A hundred million } \\
k W \cdot h\end{array}$ & $\begin{array}{c}\text { A hundred million } \\
k W \cdot h\end{array}$ & $\%$ \\
\hline 1 & $\# 8$ & 1000 & 61.47 & 64.24 & -2.77 & $-4.51 \%$ \\
\hline 2 & $\# 7$ & 1000 & 60.94 & 63.83 & -2.90 & $-4.76 \%$ \\
\hline 3 & $\# 1$ & 1000 & 62.63 & 65.20 & -2.58 & $-4.11 \%$ \\
\hline 4 & $\# 2$ & 1000 & 60.62 & 63.35 & -2.73 & $-4.50 \%$ \\
\hline 5 & $\# 3$ & 660 & 31.21 & 31.09 & 0.12 & $0.39 \%$ \\
\hline 6 & $\# 4$ & 660 & 35.31 & 35.13 & 0.18 & $0.52 \%$ \\
\hline 7 & $\# 5$ & 900 & 53.38 & 55.40 & -2.02 & $-3.79 \%$ \\
\hline 8 & $\# 6$ & 900 & 50.09 & 51.93 & -1.84 & $-3.68 \%$ \\
\hline 9 & $\# 2$ & 600 & 39.35 & 38.76 & 0.58 & $1.48 \%$ \\
\hline 10 & $\# 1$ & 600 & 33.66 & 33.21 & 0.45 & $1.32 \%$ \\
\hline 11 & $\# 9$ & 315 & 19.11 & 17.74 & 1.37 & $7.18 \%$ \\
\hline 12 & $\# 3$ & 320 & 17.29 & 16.05 & 1.24 & $7.18 \%$ \\
\hline 13 & $\# 8$ & 315 & 17.56 & 16.27 & 1.29 & $7.33 \%$ \\
\hline 14 & $\# 1$ & 320 & 14.93 & 13.84 & 1.09 & $7.27 \%$ \\
\hline 15 & $\# 1$ & 600 & 29.10 & 28.82 & 0.28 & $0.96 \%$ \\
\hline 16 & $\# 11$ & 300 & 15.70 & 14.52 & 1.18 & $7.49 \%$ \\
\hline 17 & $\# 2$ & 320 & 12.69 & 11.79 & 0.90 & $7.11 \%$ \\
\hline 18 & $\# 2$ & 600 & 33.44 & 32.93 & 0.50 & $1.50 \%$ \\
\hline 19 & $\# 4$ & 320 & 14.31 & 13.28 & 1.03 & $7.21 \%$ \\
\hline 20 & $\# 12$ & 300 & 12.89 & 11.94 & 0.95 & $7.37 \%$ \\
\hline 21 & $\# 1$ & 300 & 21.05 & 19.60 & 1.45 & $6.88 \%$ \\
\hline 22 & $\# 2$ & 300 & 21.71 & 20.16 & 1.55 & $7.13 \%$ \\
\hline 23 & $\# 3$ & 300 & 16.25 & 15.03 & 1.22 & $7.51 \%$ \\
\hline 24 & $\# 4$ & 300 & 15.24 & 14.23 & 1.02 & $6.68 \%$ \\
\hline 25 & $\# 1$ & 50 & 4.09 & 3.52 & 0.57 & $13.95 \%$ \\
\hline 26 & $\# 2$ & 50 & 3.64 & 3.19 & 0.45 & $12.36 \%$ \\
\hline 27 & $\# 3$ & 75 & 3.69 & 3.37 & 0.33 & $8.81 \%$ \\
\hline 28 & $\# 4$ & 75 & 4.02 & 3.62 & 0.39 & $9.75 \%$ \\
\hline 29 & $\# 5$ & 10 & 0.78 & 0.69 & 0.08 & $10.46 \%$ \\
\hline 30 & $\# 6$ & 10 & 0.82 & 0.71 & 0.11 & $13.20 \%$ \\
\hline 31 & $\# 1$ & 120 & 10.17 & 9.15 & 1.02 & $10.02 \%$ \\
\hline 32 & $\# 2$ & 120 & 5.08 & 4.47 & 0.61 & $11.96 \%$ \\
\hline 33 & $\# 1$ & 12 & 0.73 & 0.69 & 0.05 & $6.28 \%$ \\
\hline 34 & $\# 1$ & 350 & 21.91 & 20.49 & 1.42 & $6.50 \%$ \\
\hline 35 & $\# 2$ & 350 & 21.41 & 19.95 & 1.46 & $6.81 \%$ \\
\hline 36 & $\# 3$ & 350 & 28.11 & 26.15 & 1.95 & $6.94 \%$ \\
\hline 37 & \#4-9 & 175 & 9.77 & 9.10 & 0.68 & $6.92 \%$ \\
\hline Summation & & & 864.13 & 853.47 & 10.66 & $1.23 \%$ \\
\hline
\end{tabular}


Tab.2 Generation space of units under carbon emission trade in Shanghai grid

\begin{tabular}{c|c|c|c|c}
\hline Unit type & $\begin{array}{c}\text { Contract volume } \\
\text { (A hundred } \\
\text { million } k W \cdot h)\end{array}$ & $\begin{array}{c}\text { Electricity under } \\
\text { carbon constraint } \\
\text { (A hundred } \\
\text { million } k W \cdot h)\end{array}$ & $\begin{array}{c}\text { Difference } \\
\text { between contract } \\
\text { volume and actual } \\
\text { volume(A } \\
\text { hundred million } \\
k W \cdot h)\end{array}$ & $\begin{array}{c}\text { Percentage of the } \\
\text { difference } \%)\end{array}$ \\
\hline $900 M W$ & 349.12 & 363.96 & -14.84 & $-4.25 \%$ \\
\hline $600 M W$ & 202.07 & 199.95 & 2.12 & $1.05 \%$ \\
\hline $300 M W$ & 270.16 & 251.05 & 19.11 & $7.07 \%$ \\
\hline Others & 42.78 & 38.51 & 4.27 & $1.23 \%$ \\
\hline
\end{tabular}

In Tab.1 and Tab.2, 900MW thermal power unit has spare generating capacity under compulsory constraints of carbon emission and other units lack carbo quotas to different extent. Generally, under the constraints of carbon emission, amount of possible generation for this generation enterprise is 85.347 billion $\mathrm{kW} \cdot \mathrm{h}$, which is lower 1.066 billion $\mathrm{kW} \cdot \mathrm{h}$ than contract volume, taking the percentage of $1.23 \%$.

Under carbon emission trade, different carbon price have different impact on various scale of units, details are shown in Tab.3.

Tab.3 Generating cost of units under carbon emission for Shanghai grid (yuan/kW·h)

\begin{tabular}{c|c|c|c|c|c|c}
\hline $\begin{array}{r}\text { Carbon } \\
\text { price(yuan/t) }\end{array}$ & 50 & 100 & 150 & 300 & 500 & 1000 \\
$\begin{array}{c}\text { Cost variation of installed } \\
\text { capacity }\end{array}$ & -0.0017 & -0.003 & -0.005 & -0.010 & -0.017 & -0.034 \\
\hline $900 M W$ & 0.0004 & 0.0009 & 0.0013 & 0.0027 & 0.005 & 0.009 \\
\hline $300 M W$ & 0.0032 & 0.0064 & 0.0096 & 0.0192 & 0.032 & 0.064 \\
\hline other & 0.0047 & 0.0093 & 0.0140 & 0.0280 & 0.047 & 0.093 \\
\hline
\end{tabular}

Positive value is taken as increased cost; negative value is taken as reduced cost and 0 is taken as carbon price hardly has impact on unit cost. When carbon price is 1000yuan/t, cost for large thermal power units will be reduced. For example, cost of $900 \mathrm{MW}$ unit will reduce by $0.0343 \mathrm{yuan} / \mathrm{kW} \cdot \mathrm{h}$. But for cost for small and medium-sized units will be increased. For example, cost of $600 \mathrm{MW}$ unit will increase by $0.0089 \mathrm{yuan} / \mathrm{kW} \cdot \mathrm{h}$ and cost of $300 \mathrm{MW}$ unit will increase by $0.0640 \mathrm{yuan} / \mathrm{kW} \cdot \mathrm{h}$. Cost of other smaller units will increase by $0.0934 \mathrm{yuan} / \mathrm{kW} \cdot \mathrm{h}$, which is beyond the bearing capacity.

In the above analysis, 600MW and 300MW units can not accomplish scheduled generation because of quota constraints under carbon emission trade. Therefore carbon quotas should be bought. But on the premise of achieve scheduled generation, 900MW unit still has spare carbon quotas to make trade with carbon emission rights. 


\section{Conclusion and suggestion}

Carbon trade has made a great difference on power generation, operation, management and other aspects. It is of great significance to improve the energy conservation and the emission reduction in carbon trade of Shanghai, and guarantee society electrical safety. On the one hand, government should scientifically formulate carbon trade system, quota management system and stabilize price of carbon to improve fair carbon trade. On the other hand, power sector should take an active part in the formulation of carbon trade system and the development of low carbon technology to reduce level of carbon emission. Therefore, economic and social benefit of power sector can be improved.

\section{References}

[1] HE Jian-kun, ZHOU Jian, LIU Bin... Global Trends of Low Carbon Economy and China`s Responses [J].World Economics and Politics, 2010, (4): : 18-35

[2] NIU Hai-yan, NIU Yan-yue, XU Ting. Problems and countermeasures that our country electric power industry faces from the perspective of energy-saving and discharge-reducing [J].Science-Technology and Management,2008,10(1): 1-2

[3] Mao Yong-qing. Research on the Ways and Measurements of Low Carbonification Development of China Power Industry [D].Beijing: North China Electric Power University, 2012

[4] YU Bing-XU, Management Research of Generation enterprises based on Low Carbon Economy [J].Modern Enterprise Education,2012,(12): 253

[5] ZHANG Zhen, TAN Zhong-fu, HU Qing-hui, Energy Efficiency Analysis of China`s power industry and its Energy saving and Emission Reduction Approach [J]. Journal of Electric Power, 2010, 25(5): 360-365

[6] CHAI Zhong-xin. Cost Management and Analysis of generation enterprises. [M].Beijing: China Electric Power Press, 2011

[7] Shanghai EPA. Implementation advice on total amount control of major pollution for construction project during the national 12th Five Year-Plan period (tiral) [EB/OL]. Shanghai Environmental Protection Assessment【2012】6th

[8] The national development and reform commission on climate change, "2011 China regional power grid baseline emission factor” , China clean development mechanism (CDM) network 